\title{
UPAYA MENGURANGI CHANGE OVER TIME PADA PROSES PENJAHITAN DI SEWING LINE A20 PT. DF
}

\section{THE EFFORTS TO REDUCE CHANGE OVER TIME IN SEWING PROCESS AT SEWING LINE A2O PT. DF}

\author{
Tina Martina ${ }^{1}$, Nur Rofiqoh Utami ${ }^{2}$ dan Pratiwi Wulansari ${ }^{3}$ \\ ${ }^{1}$ Dosen Politeknik STTT Bandung, 40272, Indonesia \\ ${ }^{2}$ Mahasiswa Politeknik STTT Bandung, 40272, Indonesia \\ ${ }^{3}$ Staf Pengajar Politeknik STTT Bandung, 40272, Indonesia \\ Produksi Garmen, Politeknik STTT Bandung, 40272, Indonesia \\ E-mail: martina12sttt@gmail.com,nrofiqohutami@gmail.com, \\ pratiwiwulansari@gmail.com
}

\begin{abstract}
ABSTRAK
Pada industri pakaian jadi pelayanan dan kepuasan buyer menjadi hal penting dalam menghadapi persaingan agar dapat terus tumbuh dan berkembang. Order produksi setiap tahun terdiri dari berbagai macam style yang akan berganti setelah selesai diproduksi. Perusahaan akan melakukan penetapan waktu yang harus dicapai dalam menyelesaikan satu order, sehingga dapat berpengaruh pada efisiensi waktu proses dikarenakan seringnya aktivitas change over. Change over merupakan pergantian aktivitas produksi disuatu lini produksi dari satu produk ke produk lainnya. Metoda yang akan digunakan untuk mengurangi change over time (COT) pada lini produksi yaitu menggunakan Quick Change Over (QCO). Tujuan mengurangi COT untuk mengefisiensikan waktu proses produksi walaupun tidak untuk menambah kapasitas produksi. Waktu yang dibutuhkan selama set up mesin dalam QCO menjadi faktor yang paling lama sehingga beberapa proses set up harus disederhanakan sesuai dengan prinsip lean manufacturing. Upaya mengurangi COT pada proses penjahitan yaitu dengan penerapan pemeliharaan mesin yang terjadwal, menempatkan operator sesuai dengan skill matrix dan mempersiapkan aksesoris ketika diperlukan bagian produksi. Hasil setelah penerapan metoda QCO untuk style yang repeat order menunjukan bahwa COT line A20 mengalami penurunan, walaupun belum memenuhi standar target yang ditetapkan oleh perusahaan. Penurunan COT ini akan berdampak pada peningkatan produktivitas dan efisiensi di line A20.
\end{abstract}

Kata kunci: Change Over Time (COT), Quick Change Over (QCO), Produktivitas

\begin{abstract}
In garment production, customer service and satisfaction are two important matters that need to be maintained and to be developed in facing stiff competition. Orders of production in a yearly basis consist of different styles that will be replaced after their completion. Companies will decide the time that they require in completing those orders, therefore the decision will affect time efficiency due to the changeover. Changeover is the change of production activity in a production line from one to
\end{abstract}


another product. The method that will be used to reduce Change Over Time (COT) in the production line is the Quick Change Over (QCO). The purpose of reducing the COT is to make production time more efficient and also not having their capacity increased. The time needed to do machines set-up in QCO is the longest factor, therefore some set-up process need to be simplified in accordance to the Lean Manufacturing principles. To reduce the COT in the sewing process is by applying scheduled machine maintenance, proper placing of operator based on skill matrix and preparing the accessories needed by the production department. The result of QCO application for a repeat order style shows that COT line A20 was experiencing decline, regardless of not fulfilling the required standard targeted by the company. The COT decline will have impact towards the increase of productivity and efficiency in line A20.

Keywords: Change Over Time (COT), Quick Change Over (QCO), Productivity

\section{PENDAHULUAN}

PT DF merupakan salah satu perusahaan asing di Indonesia yang bergerak pada industri pakaian jadi dengan jenis produk yang dihasilkan berupa pakaian olahraga dan dibuat sesuai pesanan buyer atau make to order. Order dari buyer setiap tahunnya terdiri dari berbagai macam style yang akan berganti setelah order selesai di produksi. Waktu yang diperlukan ketika terjadi pergantian style dikenal dengan istilah change over time (COT). Change over dilakukan sebagai pergantian aktivitas produksi di suatu lini produksi dari satu produk ke produk lainnya. Selama proses change over berlangsung dibutuhkan waktu yang efisien, sehingga perusahaan menentukan target waktu untuk setiap change over produknya. COT di PT DF sangat bervariasi tergantung pada tingkat kesulitan style yang sedang diproduksi. Ketentuan dari perusahaan, apabila makin banyak proses penjahitan style seperti memiliki lebih dari 30 proses pengerjaan, maka COT akan semakin lama dan dikelompokan menjadi proses yang sulit. Sementara itu, sebaliknya apabila kurang dari 30 proses pengerjaan, COT menjadi lebih cepat dan dikelompokan menjadi proses yang mudah.

Produktivitas merupakan tolak ukur nilai pencapaian produksi dibandingkan dengan target yang ditentukan dan menjadi indikator kinerja produksi yang dapat dicapai. Apabila dilihat dari segi efisiensi waktu saat kegiatan produksi, penurunan waktu yang cukup signifikan akan meningkatkan nilai produktivitas. 
Efisiensi akan naik karena adanya peningkatan produktivitas, hal tersebut juga berkaitan dengan penggunaan input dalam memproduksi output. PT DF mempunyai standar target dalam pencapaian COT yaitu 4 jam yang berasal dari Realiable Source Industrial (RSI) Taiwan, yang mencakup waktu set up dan ramp up. Waktu set up merupakan lama waktu penyetelan mesin penjahitan style baru, sedangkan waktu ramp up merupakan lama waktu yang dibutuhkan sampai produk mencapai pada kecepatan yang diinginkan. Waktu set up selama ini menjadi masalah karena memerlukan waktu yang lama, meskipun order tersebut termasuk dalam repeat order. Pada proses pembuatan order seharusnya operator lebih mudah menyesuaikan, sehingga waktu set up tersebut tidak mengganggu kegiatan produksi dan COT yang dicapai dapat sesuai dengan standar target yang ditentukan perusahaan.

PT DF sudah menerapkan sistem produksi ramping atau dikenal dengan Lean Manufacturing. Penggunaan sistem tersebut dapat mengurangi pemborosan aktivitas yang tidak memberi nilai tambah pada perusahaan. Pemborosan dalam konsep lean saat change over yaitu set up, karena merupakan proses menyetel ulang dan mengatur peralatan agar sesuai dengan kebutuhan produksi yang akan berjalan di perusahaan. Beberapa proses set up harus disederhanakan agar proses produksi dapat berjalan dengan efisien. Penggunaan metoda QCO diharapkan dapat mengurangi COT sesuai dengan standar target yang ditetapkan yaitu selama 4 jam, dari order long pant style LW5BABS ke order medium pant style LW6AMYS dengan banyak proses lebih dari 30 proses yang pengerjaannya dapat memerlukan waktu kurang lebih 1 hari.

Berdasarkan latar belakang uraian masalah di atas, maka identifikasi masalah dapat dijabarkan sebagai berikut:

1. Berapakah lama waktu yang diperlukan ketika terjadi change over dari order long pant style LW5BABS ke order medium pant style LW6AMYS?

2. Bagaimana upaya perbaikan untuk mengurangi COT setelah diidentifikasi lamanya waktu COT 
pada proses penjahitan lebih dari 30 proses?

Manfaat yang dapat didapatkan dari hasil penelitian mengenai upaya mengurangi COT pada proses penjahitan di sewing line A20 akan membantu pihak industri pakaian jadi dalam mengoptimalkan efisiensi produksi dan mengurangi COT, sehingga dapat digunakan sebagai acuan dalam menentukan target COT produk yang memiliki lebih dari 30 proses pengerjaan penjahitannya.

\section{METODA PENELITIAN}

Metode yang digunakan dalam penelitian ini adalah deskriptif kuantitatif. Penelitian kuantitatif adalah suatu proses menemukan pengetahuan yang menggunakan data berupa angka sebagai alat menganalisis keterangan mengenai apa yang ingin diketahui (Kasiram (2008: 149).

Alat dan bahan yang digunakan pada penelitian ini berupa data dari perusahaan yang berkaitan dengan style yang sedang diamati yaitu data urutan dan waktu proses order long pant style LW5BABS dan order medium pant style LW6AMYS, data layout mesin order LW6AMYS, data
QCO tracking, data skill matrix operator, ceklist QCO serta pengukuran langsung proses set up mesin menggunakan stopwatch.

Adapun tahapan penelitian ini adalah :

1. Studi lapangan

Tahap ini merupakan tahap awal yang akan dilakukan untuk memulai penelitian. Tujuan dari tahap ini adalah untuk mengetahui kondisi di lapangan secara langsung, sehingga informasi yang didapat mengenai COT dari order long pant style LW5BABS ke order medium pant style LW6AMYS

2. Perumusan masalah dan tujuan penelitian

Setelah dilakukannya studi lapangan, maka perumusan masalah dalam penelitian ini adalah bagaimana upaya mengurangi COT dari order long pant style LW5BABS ke order medium pant style LW6AMYS. Tujuan penelitian ini adalah memperoleh COT sesuai target, sehingga bisa mengingkatkan produktivitas dan produk selesai tepat waktu. 
3. Studi pustaka

Membahas tentang teori-teori yang akan digunakan sebagai acuan menyelesaikan masalah.

4. Pengumpulan data

a. Mengumpulkan data saat proses set up dengan cara pengukuran langsung yang dilakukan untuk mendapatkan data waktu set up saat change over dari order long pant style LW5BABS ke order medium pant style LW6AMYS.

b. Mengumpulkan data dari departemen yang bersangkutan sesuai dengan order dan style yang sedang diteliti.

c. Melakukan diskusi dengan pihak perusahaan diantaranya departemen industrial engineering, teknisi, mekanik, supervisor sewing dan pengawas lini.

5. Pemecahan masalah

Proses pemecahan masalah dalam penelitian ini bisa dilakukan dengan cara, yaitu:

a. Menyusun langkah-langkah perbaikan sesuai dengan metoda QCO. b. Mempersiapkan segala sesuatu yang diperlukan sebelum COT berlangsung.

6. Diskusi

Pada tahap ini dilakukan penelitian terhadap hasil yang telah diperoleh dari pemecahan masalah. Penelitian tersebut mengenai penggunaan metoda QCO dalam upaya untuk mengurangi COT saat proses set up terhadap produktivitas.

7. Kesimpulan dan saran

Tahap terakhir dalam penelitian ini adalah penarikan kesimpulan dan saran untuk pemecahan masalah yang terjadi.

\section{HASIL DAN PEMBAHASAN}

Upaya perbaikan untuk mengurangi COT pada proses penjahitan dengan lebih dari 30 proses berdasarkan metode QCO dilakukan pada order long pant style LW5BABS ke order medium pant style LW6AMYS. Order long pant style LW5BABS memerlukan 27 operator, nilai IE 2,53 dan jumlah proses pengerjaan penjahitannya 41 proses sedangkan order medium pant style LW6AMYS yang memerlukan 28 operator, nilai IE 1,57 dan jumlah proses pengerjaan penjahitannya 40 
proses. Nilai Industrial Engineering (IE) merupakan suatu angka yang dibuat berdasarkan tingkat kesulitan produk, kemudian akan menentukan lama change over time dan harga jual dari suatu produk tersebut.

Data yang dapat dikumpulkan berdasarkan pengamatan seperti data urutan dan waktu proses order long pant style LW5BABS ke order medium pant style LW6AMYS, data layout mesin order medium pant style LW6AMYS, data QCO tracking, data skill matrix operator dan ceklist $Q C O$. Data QCO tracking berisi informasi mengenai masalah yang dihadapi saat change over dan lama waktu masalah tersebut terjadi. Selanjutnya, data skill matrix operator memberikan informasi mengenai kemampuan operator di lini penjahitan, dengan adanya data tersebut akan mempermudah pengawas lini dalam menempatkan operator sesuai dengan kemampuan menjahit dan penguasaan mesin penjahitan. Terakhir, ceklist QCO yaitu berupa persiapan-persiapan yang harus dipenuhi sebelum dan saat change over dimulai. Diharapkan dengan adanya ceklist QCO ini, COT bisa memenuhi standar target yang ditetapkan oleh perusahaan. Berikut disajikan design order long pant style LWBABS pada Gambar 3.1 dan design order medium pant style LW6AMYS pada Gambar 3.2.

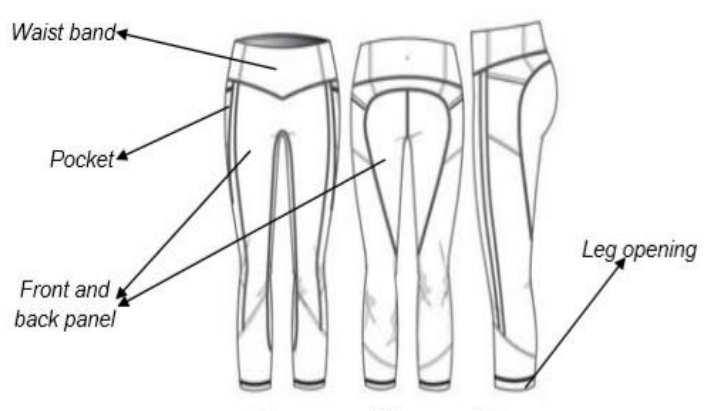

(a)

(b) (c)

Sumber: Bagian Industrial Engineering PT DF

Gambar 3.1 Design order long pant style LW5BABS

Keterangan:

(a) Bagian depan (b) Bagian belakang (c) Bagian samping long pant style LW5BABS

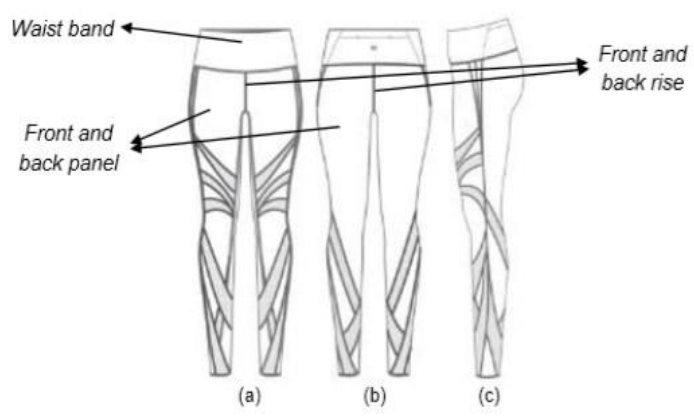

Sumber: Bagian Industrial Engineering

PT DF

Gambar 3.2 Design order medium pant style LW6AMYS 
Keterangan:

(a) Bagian depan (b) Bagian belakang (c) Bagian samping medium pant style LW6AMYS
Urutan dan waktu proses pembuatan order long pant style LW5BABS disajikan pada pada Tabel 3.1 dan order medium pant style LW6AMYS pada Tabel 3.2.

Tabel 3.1 Urutan dan waktu proses pembuatan order long pant style LW5BABS

\begin{tabular}{|c|c|c|c|c|}
\hline Komponen & $\begin{array}{c}\text { No. } \\
\text { Proses }\end{array}$ & Nama Proses & $\begin{array}{l}\text { Waktu } \\
\text { (detik) }\end{array}$ & Mesin \\
\hline \multirow{10}{*}{ Waist band } & 01 & $\begin{array}{l}\text { Pasang lapisan kantong } \\
\text { ke band belakang } 1 \\
\text { mobilon dan bobok }\end{array}$ & 25 & Obras 4B \\
\hline & 02 & Stik lubang kantong & 14 & Overdeck 2J3B \\
\hline & 03 & Tanda band belakang & 10 & Manual \\
\hline & 04 & $\begin{array}{l}\text { Tacking gabung lubang } \\
\text { kantong }\end{array}$ & 27 & Single needle \\
\hline & 05 & $\begin{array}{l}\text { Tanda dan } \text { gabung } \\
\text { lubang kantong } 3 \text { sisi ( } 2 \\
\text { kali jahit) dan buang } \\
\text { benang }\end{array}$ & 91 & Overdeck 1J2B \\
\hline & 06 & $\begin{array}{l}\text { Tanda dan bartack } \\
\text { lubang kantong }\end{array}$ & 28 & Bartack \\
\hline & 07 & Gabung kantong kedua sis & 18 & \multirow{2}{*}{ Obras 4B } \\
\hline & 08 & $\begin{array}{l}\text { Gabung samping band } \\
\text { lengkung }\end{array}$ & 37 & \\
\hline & 09 & $\begin{array}{l}\text { Tacking bawah kantong } \\
\text { ke band titik }\end{array}$ & 15 & Single needle \\
\hline & 10 & Running band keliling & 40 & Obras 3B \\
\hline \multirow[t]{2}{*}{$\begin{array}{c}\text { Front panel } \\
\text { and Back } \\
\text { panel }\end{array}$} & 11 & $\begin{array}{l}\text { Sampong gabung mesh } \\
\text { ke inseam bawah panel } \\
\text { depan (vertikal) }\end{array}$ & 30 & \multirow[t]{2}{*}{$\begin{array}{c}\text { Feed of the arm } \\
\text { 4J6B }\end{array}$} \\
\hline & 12 & Sampong gabung mesh & 216 & \\
\hline
\end{tabular}




\begin{tabular}{|c|c|c|c|c|}
\hline Komponen & $\begin{array}{c}\text { No. } \\
\text { Proses }\end{array}$ & Nama Proses & $\begin{array}{l}\text { Waktu } \\
\text { (detik) }\end{array}$ & Mesin \\
\hline & & $\begin{array}{l}\text { ke atas panel depan } \\
\text { lengkung (horizontal) }\end{array}$ & & \\
\hline & 13 & $\begin{array}{l}\text { Tanda dan sampong stik } \\
\text { panel samping atas ( } 1 \\
\text { lembar) }\end{array}$ & 54 & \\
\hline & 14 & $\begin{array}{l}\text { Sampong gabung panel } \\
\text { ke samping atas panel } \\
\text { depan }\end{array}$ & 36 & \\
\hline & 15 & $\begin{array}{l}\text { Sampong gabung mesh } \\
\text { ke bawah panel depan } \\
\text { (vertikal) }\end{array}$ & 56 & \\
\hline & 16 & $\begin{array}{l}\text { Sampong gabung mesh } \\
\text { ke samping bawah panel } \\
\text { depan (vertikal) }\end{array}$ & 37 & \\
\hline & 17 & $\begin{array}{l}\text { Sampong gabung mesh } \\
\text { ke bawah panel belakang } \\
\text { (vertikal) }\end{array}$ & 100 & \\
\hline & 18 & $\begin{array}{l}\text { Gosok panel depan atas } \\
\text { dan panel belakang } \\
\text { bawah }\end{array}$ & 64 & Gosok \\
\hline & 19 & Tanda panel depan atas & 40 & Manual \\
\hline & 20 & $\begin{array}{l}\text { Obras potong panel } \\
\text { depan atas kedua sisi }\end{array}$ & 44 & \multirow[t]{2}{*}{ Obras 3B } \\
\hline \multirow{4}{*}{$\begin{array}{c}\text { Front and } \\
\text { back rise and } \\
\text { inseam }\end{array}$} & 21 & Obras gusset 3 sisi & 20 & \\
\hline & 22 & $\begin{array}{l}\text { Sampong gabung front } \\
\text { rise }\end{array}$ & 25 & \multirow{3}{*}{$\begin{array}{c}\text { Feed of the arm } \\
\text { 4J6B }\end{array}$} \\
\hline & 23 & $\begin{array}{l}\text { Sampong gabung gusset } \\
\text { ke panel belakang dan } \\
\text { gabung back rise }\end{array}$ & 39 & \\
\hline & 24 & Tanda inseam and & 65 & \\
\hline
\end{tabular}




\begin{tabular}{|c|c|c|c|c|}
\hline Komponen & $\begin{array}{c}\text { No. } \\
\text { Proses }\end{array}$ & Nama Proses & $\begin{array}{l}\text { Waktu } \\
\text { (detik) }\end{array}$ & Mesin \\
\hline & & gabung inseam & & \\
\hline & 25 & $\begin{array}{l}\text { Sampong gabung mesh } \\
\text { ke atas panel depan } \\
\text { sampai panel belakang }\end{array}$ & 44 & \\
\hline & 26 & $\begin{array}{l}\text { Sampong gabung mesh } \\
\text { ke bawah panel depan } \\
\text { sampai panel belakang }\end{array}$ & 42 & \\
\hline & 27 & $\begin{array}{l}\text { Sampong gabung mesh } \\
\text { ke samping bawah panel } \\
\text { belakang (vertikal) }\end{array}$ & 40 & \\
\hline & 28 & $\begin{array}{l}\text { Tacking inseam dan } \\
\text { gusset }\end{array}$ & 144 & \multirow[t]{2}{*}{ Single needle } \\
\hline & 29 & $\begin{array}{l}\text { Tacking panel depan dan } \\
\text { belakang }\end{array}$ & 224 & \\
\hline \multirow{3}{*}{ Sideseam } & 30 & Sisip samping kedua sisi & 48 & Obras 4B \\
\hline & 31 & $\begin{array}{l}\text { Sampong gabung } \\
\text { samping }\end{array}$ & 94 & $\begin{array}{c}\text { Feed of the arm } \\
4 \mathrm{~J} 6 \mathrm{~B}\end{array}$ \\
\hline & 32 & Tacking samping & 176 & Bartack \\
\hline \multirow{5}{*}{$\begin{array}{l}\text { Attach waist } \\
\text { band to body }\end{array}$} & 33 & Tanda band & 10 & Manual \\
\hline & 34 & $\begin{array}{l}\text { Pasang band ke body } \\
\text { keliling samakan tulang }\end{array}$ & 52 & Obras 4B \\
\hline & 35 & Stik band keliling & 46 & Overdeck 3J5B \\
\hline & 36 & Tacking band & 16 & \multirow{2}{*}{ Single needle } \\
\hline & 37 & Pasang label ke band & 16 & \\
\hline \multirow{3}{*}{ Bottom hem } & 38 & $\begin{array}{l}\text { Corong binding ke lubang } \\
\text { kaki keliling }\end{array}$ & 68 & Corong 3J5B \\
\hline & 39 & $\begin{array}{l}\text { Tanda dan sambung } \\
\text { ujung binding dan sisip }\end{array}$ & 64 & Single needle \\
\hline & 40 & Stik sambung binding & 58 & Overdeck 3J5B \\
\hline
\end{tabular}




\begin{tabular}{|c|c|l|c|c|}
\hline Komponen & $\begin{array}{c}\text { No. } \\
\text { Proses }\end{array}$ & \multicolumn{1}{|c|}{ Nama Proses } & $\begin{array}{c}\text { Waktu } \\
\text { (detik) }\end{array}$ & Mesin \\
\hline & 41 & $\begin{array}{l}\text { Tabang kaki } \\
\text { kaki }\end{array}$ & 43 & Single needle \\
\cline { 2 - 5 } & 4 binding lubang & \\
\hline
\end{tabular}

Sumber: Bagian Industrial Engineering PT DF

Tabel 3.2 Urutan dan waktu proses pembuatan order medium pant style LW6AMYS

\begin{tabular}{|c|c|c|c|c|}
\hline Komponen & $\begin{array}{c}\text { No. } \\
\text { Proses }\end{array}$ & Nama Proses & $\begin{array}{l}\text { Waktu } \\
\text { (detik) }\end{array}$ & Mesin \\
\hline \multirow{11}{*}{$\begin{array}{c}\text { Inner } \\
\text { waistband } \\
\text { card pkt*1 + } \\
\text { assembly } \\
\text { inner \& } \\
\text { outer wb }\end{array}$} & 01 & $\begin{array}{l}\text { Obras gabung band luar } \\
\text { dan band dalam }\end{array}$ & 48 & Obras 4B \\
\hline & 02 & $\begin{array}{l}\text { Stik band luar dan band } \\
\text { dalam }\end{array}$ & 40 & Overdeck 3J5B \\
\hline & 03 & $\begin{array}{l}\text { Pasang kantong ke band } \\
\text { dalam bobok dan pasang } \\
\text { kantong ke band luar }\end{array}$ & 36 & Overdeck 1J2B \\
\hline & 04 & $\begin{array}{lll}\text { Obras } & \text { lubang } & \text { kantong } \\
\text { band } & \text { dalam } & \text { dengan } \\
\text { mobilon } & & \end{array}$ & 10 & Obras 4B \\
\hline & 05 & Stik lubang kantong & 14 & Overdeck 2J3B \\
\hline & 06 & $\begin{array}{l}\text { Tacking gabung lubang } \\
\text { kantong kedua sisi }\end{array}$ & 32 & Single needle \\
\hline & 07 & Obras kantong & 20 & \multirow{2}{*}{ Obras 4B } \\
\hline & 08 & $\begin{array}{l}\text { Obras gabung band } \\
\text { belakang }\end{array}$ & 36 & \\
\hline & 09 & $\begin{array}{l}\text { Pasang karet ke band } \\
\text { belakang }\end{array}$ & 18 & \multirow{3}{*}{ Overdeck 2J3B } \\
\hline & 10 & $\begin{array}{l}\text { Stik lubang kantong sisi } \\
\text { yang lain }\end{array}$ & 22 & \\
\hline & 11 & Stik band belakang & 28 & \\
\hline
\end{tabular}




\begin{tabular}{|c|c|c|c|c|}
\hline Komponen & $\begin{array}{c}\text { No. } \\
\text { Proses }\end{array}$ & Nama Proses & $\begin{array}{l}\text { Waktu } \\
\text { (detik) }\end{array}$ & Mesin \\
\hline & 12 & $\begin{array}{l}\text { Bartack lubang kantong } \\
\text { band }\end{array}$ & 20 & Bartack \\
\hline & 13 & Obras band depan & 36 & Obras 4B \\
\hline & 14 & Stik band depan & 41 & Overdeck 3J5B \\
\hline & 15 & Obras running band & 41 & Obras 3B \\
\hline \multirow{3}{*}{$\begin{array}{l}\text { Side patch } \\
\text { pkt*2 }\end{array}$} & 16 & $\begin{array}{l}\text { Lipat dan stik lubang } \\
\text { kantong }\end{array}$ & 30 & Overdeck 2J4B \\
\hline & 17 & $\begin{array}{l}\text { Tacking kantong kedua sisi } \\
\text { dan lipat ujung kantong }\end{array}$ & 64 & Single needle \\
\hline & 18 & Stik bawah kantong & 38 & Overdeck 2J4B \\
\hline \multirow{11}{*}{$\begin{array}{l}\text { Assembly } \\
\text { body }\end{array}$} & 19 & $\begin{array}{l}\text { Obras gambung atas body } \\
\text { belakang }\end{array}$ & 24 & Obras 4B \\
\hline & 20 & 20 Stik atas body belakang & 20 & Overdeck 3J5B \\
\hline & 21 & $\begin{array}{l}\text { Sampong gabung samping } \\
\text { depan }\end{array}$ & 62 & \multirow{2}{*}{$\begin{array}{c}\text { Feed of the arm } \\
4 \mathrm{~J} 6 \mathrm{~B}\end{array}$} \\
\hline & 22 & $\begin{array}{l}\text { Sampong gabung samping } \\
\text { belakang }\end{array}$ & 65 & \\
\hline & 23 & $\begin{array}{l}\text { Obras gabung bawah panel } \\
\text { depan ke panel belakang }\end{array}$ & 48 & Obras 4B \\
\hline & 24 & $\begin{array}{l}\text { Stik bawah panel depan ke } \\
\text { panel belakang }\end{array}$ & 39 & Overdeck 2J4B \\
\hline & 25 & Sampong gabung back rise & 18 & Feed of the arm \\
\hline & 26 & $\begin{array}{l}\text { Sampong gabung panel } \\
\text { belakang lengkung }\end{array}$ & 71 & $4 J 6 B$ \\
\hline & 27 & Bartack lubang kantong & 40 & Bartack \\
\hline & 28 & $\begin{array}{l}\text { Sampong gabung inseam } \\
\text { depan }\end{array}$ & 58 & $\begin{array}{c}\text { Feed of the arm } \\
4 \mathrm{~J} 6 \mathrm{~B}\end{array}$ \\
\hline & 29 & Zig zag pasang tape ke & 52 & Zig-zag 4T \\
\hline
\end{tabular}




\begin{tabular}{|c|c|c|c|c|}
\hline Komponen & $\begin{array}{c}\text { No. } \\
\text { Proses }\end{array}$ & Nama Proses & $\begin{array}{l}\text { Waktu } \\
\text { (detik) }\end{array}$ & Mesin \\
\hline & & hemming bawah & & \\
\hline & 30 & $\begin{array}{l}\text { Sampong gabung inseam } \\
\text { belakang }\end{array}$ & 85 & $\begin{array}{c}\text { Feed of the arm } \\
\text { 4J6B }\end{array}$ \\
\hline \multirow{6}{*}{$\begin{array}{l}\text { Attaching } \\
\text { waist band }\end{array}$} & 31 & Tanda band & 6 & Manual \\
\hline & 32 & $\begin{array}{l}\text { Tacking gabung band } \\
\text { depan ke body (bobok) }\end{array}$ & 25 & \multirow[t]{2}{*}{ Single needle } \\
\hline & 33 & $\begin{array}{l}\text { Tacking gabung band ke } \\
\text { body samakan seam }\end{array}$ & 45 & \\
\hline & 34 & $\begin{array}{l}34 \text { Obras gabung band ke } \\
\text { body }\end{array}$ & 44 & Overlock \\
\hline & 35 & Stik band & 43 & Overdeck 3J5B \\
\hline & 36 & Tacking band & 16 & Single needle \\
\hline \multirow[t]{4}{*}{ Leg opening } & 37 & Sisip lubang kaki & 35 & Manual \\
\hline & 38 & Stik hemming bawah & 68 & Overdeck 3J5B \\
\hline & 39 & $\begin{array}{l}\text { Tacking bawah, crotch dan } \\
\text { inseam }\end{array}$ & 52 & \multirow[t]{2}{*}{ Single needle } \\
\hline & 40 & Pasang label & 17 & \\
\hline
\end{tabular}

Sumber: Bagian Industrial Engineering PT DF

Berdasarkan tabel urutan proses dan waktu pembuatan order long pant LW5BABS dan order medium pant LW6AMYS tersebut, dilakukan upaya perbaikan berupa penerapan metode QCO yang merupakan salah satu metode improvement dari lean manufacturing system yang dapat digunakan untuk mempercepat waktu saat melakukan set up ketika change over dari memproduksi satu jenis produk ke model produk lainnya dengan cara menyederhanakan beberapa kegiatan yang menyebabkan proses produksi tidak efisien.

1. Mengubah set up internal menjadi eksternal

Tujuan dari adanya QCO pada aktivitas ini adalah untuk mengurangi kegiatan set up internal semaksimal mungkin. Dari kegiatan set up ini akan 
menghasilkan layout mesin yang baru dan penyesuaian operator terhadap perubahan operasi penjahitan yang dikerjakan. Apabila ada kegiatan set up yang tidak bisa diubah, maka akan dicari cara untuk memperpendek waktunya.

2. Penempatan ulang operator berdasarkan skill mapping

Setiap lini penjahitan terdiri dari beberapa operator yang mahir dan kurang mahir. Untuk itu, pengawas lini dituntut untuk bisa melakukan pemetaan operator sesuai dengan kemampuan dalam menguasai mesin penjahitan berdasarkan Skill matrix operator. Hal ini berfungsi untuk membantu kelancaran saat proses produksi style baru dengan menentukan operator pada tingkat kesulitan penjahitan tertentu sehingga tidak menyebabkan timbulnya masalah seperti bottle neck karena jahitan sulit maupun kurangnya kemampuan operator, sehingga apabila penempatannya sesuai maka akan mengurangi COT saat change over.

3. Persiapan sebelum layout Upaya mengurangi waktu change over dapat dilakukan melalui persiapan set up sebaik mungkin dengan pembuatan ceklist $Q C O$ yang berisi segala sesuatu yang dibutuhkan. Pengontrolan ceklist dilakukan oleh bagian IE. Ceklist QCO berbentuk form yang dibuat untuk memperlancar proses set up yang diantaranya berisi tentang rencana change over, line balancing, skill mapping operator, kebutuhan change over, jadwal PP Meeting, setting mesin hingga pengecekan kualitas jahitan saat change over agar sesuai dengan standar yang diberikan serta memudahkan saat akan dilakukan change over. Berikut flowchart ceklist QCO dalam Tabel 3.3 
Tabel 3.3 Flowchart Ceklist Quick Change Over

\begin{tabular}{|c|c|c|c|c|}
\hline Flowchart & $\begin{array}{c}\text { Penanggung } \\
\text { Jawab }\end{array}$ & Aktivitas & Waktu & Dokumen \\
\hline $\begin{array}{l}\text { Pembuatan } \\
\text { rencana } \\
\text { change over }\end{array}$ & Planner & $\begin{array}{c}\text { Membuat rencana } \\
\text { change over. }\end{array}$ & $\begin{array}{c}1 \text { bulan } \\
\text { sebelum } \\
\text { change } \\
\text { over }\end{array}$ & Ceklist QCO \\
\hline $\begin{array}{l}\text { Persiapan } \\
\text { layout } \\
\text { penjahitan }\end{array}$ & $\begin{array}{l}\text { Industrial } \\
\text { engineering }\end{array}$ & $\begin{array}{l}\text { Menyiapkan } \\
\text { layout, line } \\
\text { balancing. }\end{array}$ & $\begin{array}{c}\mathrm{H}-3 \\
\text { change } \\
\text { over }\end{array}$ & Ceklist QCO \\
\hline $\begin{array}{l}\text { Penempatan } \\
\text { operator } \\
\text { sesuai } \\
\text { kemampuan }\end{array}$ & $\begin{array}{c}\text { Supervisor } \\
\text { sewing dan } \\
\text { pengawas lini }\end{array}$ & $\begin{array}{c}\text { Merencanakan } \\
\text { penempatan } \\
\text { operator sesuai } \\
\text { kemampuannya } \\
\text { saat layout. }\end{array}$ & $\begin{array}{c}\mathrm{H}-3 \\
\text { change } \\
\text { over }\end{array}$ & Ceklist QCO \\
\hline \pm & & $\begin{array}{c}\text { Memberikan } \\
\text { informasi change }\end{array}$ & $\mathrm{H}-2$ & \\
\hline $\begin{array}{c}\text { Pemberian } \\
\text { informasi } \\
\text { change over }\end{array}$ & $\begin{array}{c}\text { Kepala Bagian } \\
\text { Sewing }\end{array}$ & $\begin{array}{c}\text { over kepada It, } \\
\text { Supervisor } \\
\text { Sewing, Pengawas }\end{array}$ & $\begin{array}{c}\text { change } \\
\text { over }\end{array}$ & Ceklist QCO \\
\hline$\downarrow$ & & $\begin{array}{l}\text { Lini Mekanik, QC, } \\
\text { QA dan Teknisi. }\end{array}$ & & \\
\hline $\begin{array}{l}\text { Persiapkan } \\
\text { mesin } \\
\text { sesuai } \\
\text { dengan } \\
\text { layout }\end{array}$ & Mekanik & $\begin{array}{l}\text { Menyiapkan mesin } \\
\text { sesuai layout dan } \\
\text { line balancing } \\
\text { yang diberikan }\end{array}$ & $\begin{array}{c}\mathrm{H}-2 \\
\text { change } \\
\text { over }\end{array}$ & Ceklist QCO \\
\hline$\downarrow$ & & bagian IE. & & \\
\hline
\end{tabular}




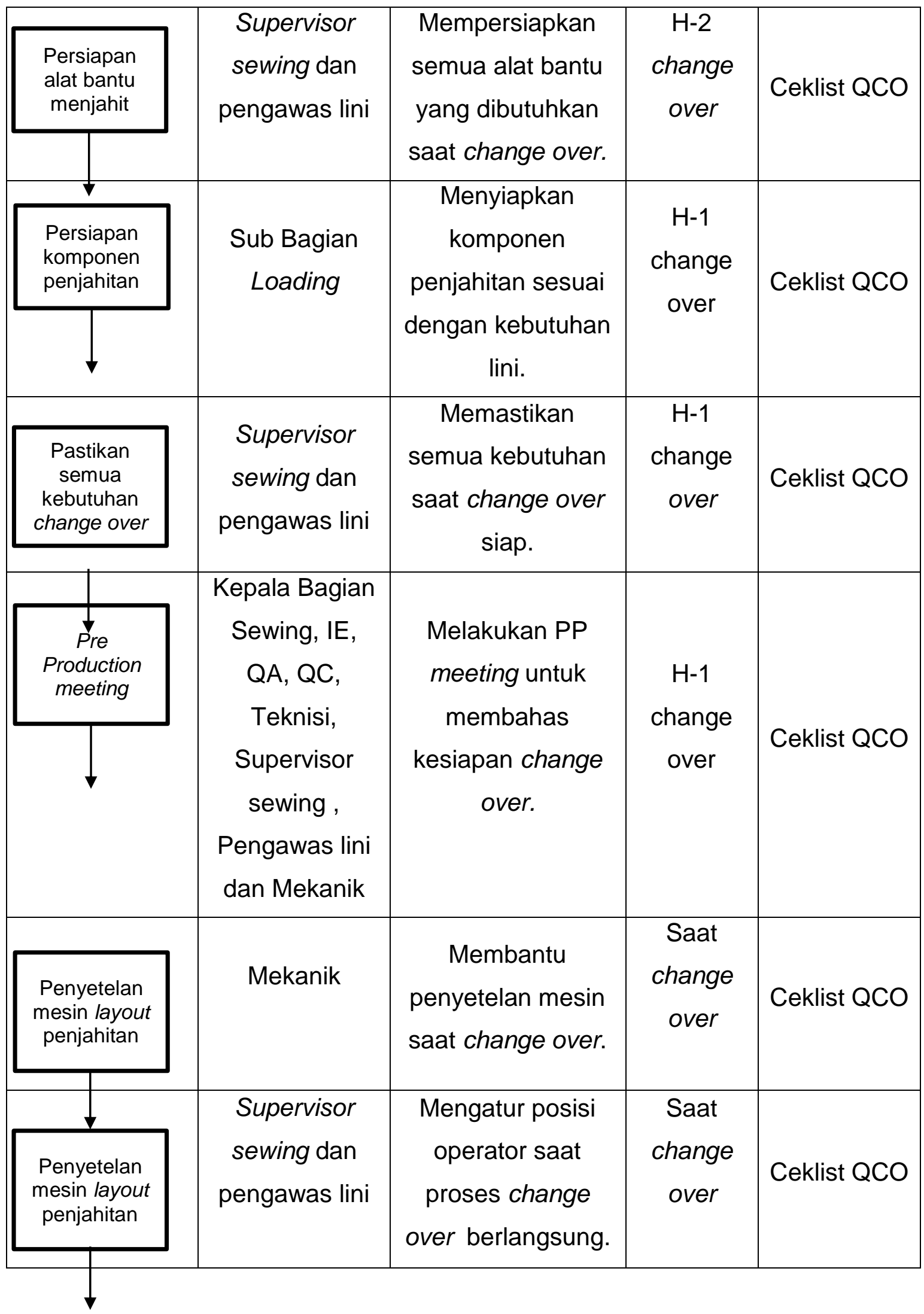




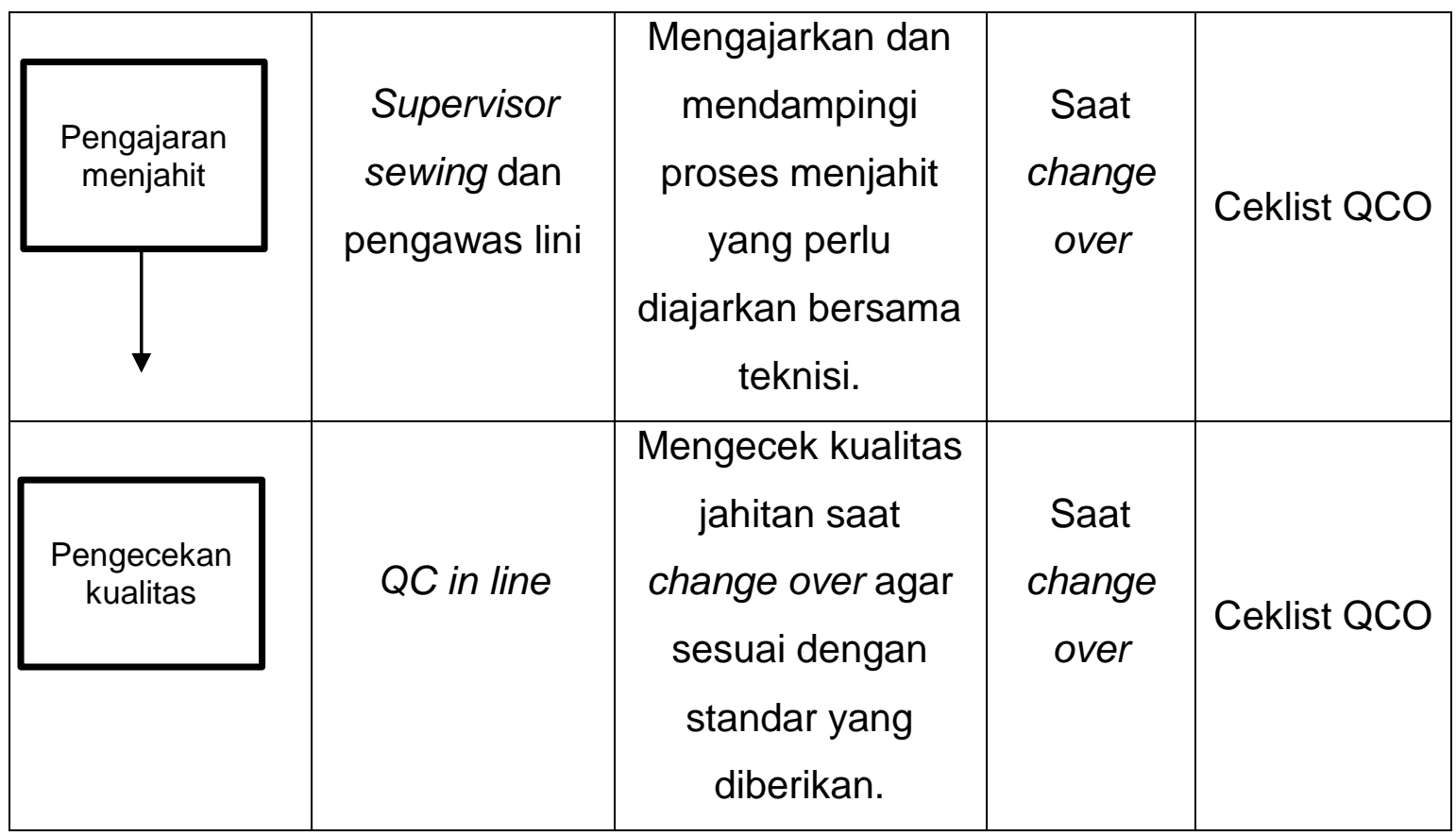

Sumber: Bagian Industrial Engineering PT DF

\subsection{Evaluasi Hasil Penerapan Quick Change Over}

Berdasarkan pada penerapan metode QCO saat change over dari order long pants style LW5BABS ke order medium pants style LW6AMYS, dengan adanya perbaikan set up internal ke set up eksternal sehingga dapat mengurangi waktu tunggu maka didapat waktu set up yang awalnya 944 menit (15 jam 44 menit) menjadi 470 menit (7 jam 50 menit) dengan hasil penurunan waktu sebesar 474 menit (7 jam 54 menit). Cara perhitungan COT yaitu dari mulai layout style LW6AMYS sampai menghasilkan 1 pcs style LW6AMYS tersebut.Nilai penurunan yang dihasilkan tersebut disebabkan karena semua keperluan, baik set up mesin maupun kendala yang mungkin akan dihadapi seperti skill mapping operator sudah dipersiapkan dengan baik, sehingga saat change over dilakukan kendala yang dihadapi lebih sedikit.

Penurunan COT ini akan berdampak pada peningkatan produktivitas, dari hasil penelitian didapatkan hasil sebelum penerapan metoda QCO sebesar 0,92 pcs/man hour dan sesudah penerapan metoda QCO sebesar 1,26 pcs/man hour. Hal ini juga berdampak pada kenaikan efisiensi di line A20 yang awalnya 58\% menjadi $78 \%$. Upaya mengurangi $C O T$ proses penjahitan yang lebih dari 30 proses dilakukan dengan menerapkan 
pemeliharaan mesin yang terjadwal, mempertimbangkan skill operator seperti penempatan operator sesuai dengan skill matrix yang ada, sehingga terhindar dari bottle neck. Terakhir faktor eksternal di bagian gudang aksesoris dalam menyiapkan aksesoris untuk lini yang akan melakukan change over. Pencapaian output, produktivitas dan efisiensi lini penjahitan A20 disajikan pada Tabel 3.4 .

Tabel 3.4. Pencapaian Output dan Produktivitas Lini Penjahitan A20

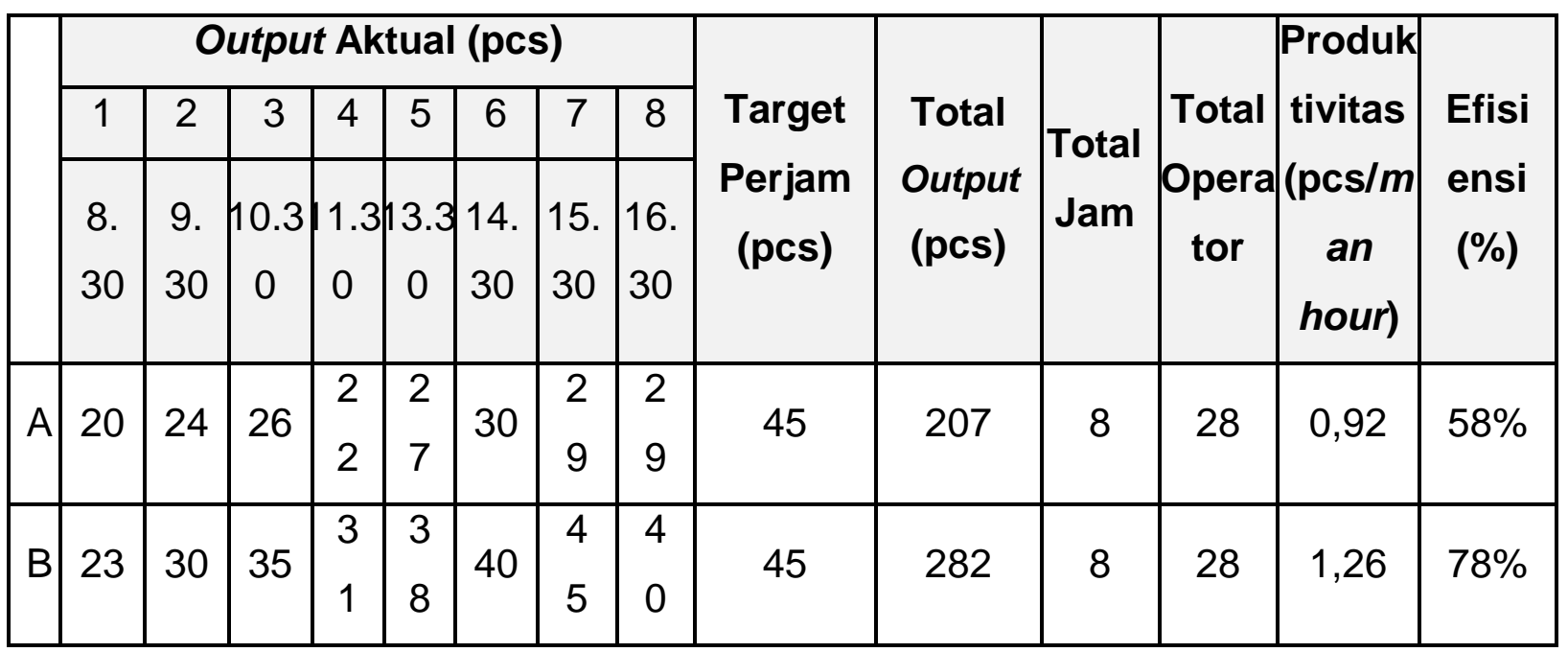

Sumber: Bagian Industrial Engineering PT DF

Keterangan:

A : Sebelum perbaikan set up (menit)

B : Sesudah perbaikan set up (menit)

Target perjam $=45 \mathrm{pcs} / \mathrm{jam}$

Jumlah jam kerja $=8 \mathrm{Jam} /$ hari
Quantity order $\mathrm{A}=5.728 \mathrm{pcs}$

Quantity order B $=3.580$ pcs

\begin{tabular}{|l|}
\hline Produktivitas \\
$\frac{\text { Jumlah } \text { Output }}{\text { (Jumlah operator x jumlah jam kerja) }}$ \\
\hline
\end{tabular}

Produktivitas $\mathrm{A}=207 /(28 \times 8)=0,92$ $\mathrm{pcs} /$ man hour

Produktivitas $\mathrm{B}=282 /(28 \times 8)=1,26$ $\mathrm{pcs} /$ man hour
Efisiensi $\quad: \frac{\text { Jumlah Output }}{\text { Target per hari }} \times 100 \%$

Efisiensi $A=207 /(45 \times 8) \times 100$ $\%=58 \%$

Efisiensi $B=282 /(45 \times 8) \times 100$ $\%=78 \%$ 


\section{KESIMPULAN}

Penelitian tentang upaya mengurangi COT pada proses penjahitan di sewing line A20 dari order long pant style LW5BABS ke order medium pant style LW6AMYS, dapat ditarik kesimpulan sebagai berikut:

1. Waktu yang diperlukan ketika terjadi change over dari order long pant style LW5BABS ke order medium pant style LW6AMYS, yaitu 470 menit (7 jam 50 menit) dikarenakan beberapa hal seperti faktor mesin, skill operator, dan faktor eksternal. Hal tersebut masih belum sesuai dengan standar target yang ditetapkan oleh perusahaan sesuai RSI Taiwan yaitu 4 jam.

2. Upaya mengurangi COT pada proses penjahitan yang lebih dari
30 proses, yaitu dengan penelitian terhadap masalah yang terjadi dan kemudian penerapan perbaikan yang telah dilakukan, seperti:

- Faktor mesin: bagian maintenance menerapkan pemeliharaan mesin yang terjadwal agar usia pakai mesin menjadi lama dan meminimalisir kerusakan saat digunakan.

- Skill operator: dilakukan penempatan operator sesuai dengan skill matrix yang ada, agar terhindar dari bottle neck dan proses produksi menjadi cepat sesuai target.

- Faktor eksternal : bagian gudang aksesoris lebih mempersiapkan aksesoris saat diminta bagian produksi yang akan melakukan change over. 


\section{DAFTAR PUSTAKA}

1. Bagian Industrial Engineering. 2018. Company Profile. Jakarta Utara: PT Dragon Forever

2. Garspersz, Vincent. (1998): Manajemen Produktivitas Total, Jakarta, Gramedia Pustaka Utama.

3. Indonesia, Shift. Mengurangi Waktu Changeover untuk Kualitas Produk dan Efektifitas Biaya dengan SMED, data diperoleh melalui situs internet: http://shiftindonesia.com/mengurangi-waktu-changeover-untukkualitas-produkdan-efektifitas-biaya-dengan-smed/ Diunduh pada tanggal 9 Maret 2018.

4. Indonesia, Shift. Quick Changeover untuk Tingakatan Fleksibilitas Produksi, data diperoleh melalui situs internet: http://shiftindonesia.com/quick-changeoveruntuk-tingkatkanfleksibilitas-produksi/ Diunduh pada tanggal 9 Maret 2018.

5. Liker, Jefrey. K. (2006): The Toyota Way, Jakarta: Erlangga.

6. Ohno, Taiichi. (1988): Toyota Production System, Portland, Productivity Press.

7. Radyanto, Riza. Peningkatan Produktivitas Industri Garmen, data diperoleh melalui situs internet: http://google.co.id/peningkatanproduktivitasindustrigarmen Diunduh pada tanggal 9 Maret 2018.

8. Shingo, Shigeo. (1996): Quick Changeover for operatos: The SMED System, Portland Oregon: Productivity Press.

9. T. Hidayat Alex. (2016): Garment Planning and Production Process Management, Bandung, Sekolah Tinggi Teknologi Tekstil Bandung.

10. Tim Pusat Bahasa Depdiknas. (2008): Kamus Besar Bahasa Indonesia, Jakarta, Pusat Bahasa Departemen Pendidikan Nasional.

11. Wignosoebroto, Sritomo. (2000): Teknik Analisa untuk Peningkatan Produktivitas Kerja, Surabaya.

12. (t.thn.). Dipetik Maret 9, 2018, dari https://ipqi.org/apa-itu-changeover-dan-setuptime/ 